\title{
Options for arterial cannulation to provide antegrade cerebral perfusion: Everything old is new again
}

\author{
Joseph S. Coselli, MD, ${ }^{\mathrm{a}, \mathrm{b}}$ and Ourania Preventza, MD ${ }^{\mathrm{a}, \mathrm{b}}$
}

\footnotetext{
From the a Division of Cardiothoracic Surgery, Baylor College of Medicine, Houston, Tex; and ${ }^{\mathrm{b}}$ Department of Cardiovascular Surgery, Texas Heart Institute, Houston, Tex.

Disclosures: Authors have nothing to disclose with regard to commercial support.

Received for publication Dec 8, 2015; accepted for publication Dec 10, 2015; available ahead of print Jan 22, 2016.

Address for reprints: Joseph S. Coselli, MD, One Baylor Plaza, BCM 390, Houston, TX 77030 (E-mail: jcoselli@ bcm.edu).

J Thorac Cardiovasc Surg 2016;151:1079-80

$0022-5223 / \$ 36.00$

Copyright (c) 2016 by The American Association for Thoracic Surgery

http://dx.doi.org/10.1016/j.jtcvs.2015.12.017
}

Some clinical problems have multiple, nearly equally effective solutions, with no clear winner among them. Craig Miller frequently points out that there is more than one way to skin a cat. Cat lovers will be relieved to know that "cat" does not refer to the mammal but rather the catfish. The somewhat easy skinning process can begin at the head, near the tail fin, or laterally. In moderately skilled hands, all 3 options are equally effective.

Over the decades, several cerebral protection strategies have been used during aortic arch reconstruction. These include simple deep hypothermia as initially described by Griepp and colleagues, ${ }^{1}$ providing a quiet, dry, unencumbered surgical field. Hypothermia alone continues to produce excellent results, including extremely low morbidity and mortality. Retrograde cerebral perfusion (RCP), initially popularized by Ueda and colleagues, ${ }^{2,3}$ has been used frequently in conjunction with deep hypothermia. The popularity of RCP has declined in recent years; today, it is used primarily in select patients with significant atherosclerotic load or for whom alternative techniques are considered less appropriate.

Antegrade cerebral perfusion (ACP) was initially used successfully by De Bakey and colleagues ${ }^{4}$ by directly cannulating the innominate and left common carotid arteries; decades later, ACP was popularized by Kazui and colleagues. ${ }^{5}$ In the hands of dedicated teams, deep hypothermia alone, RCP, and ACP produce similarly excellent results.

Most frequently, ACP is established via the right axillary artery by direct cannulation or a small side graft. An increasingly popular alternative inflow site is the innominate artery. In this issue of the Journal, Jassar and colleagues $^{6}$ at the University of Pennsylvania report their experience with 100 elective hemiarch reconstructions with ACP established by direct innominate artery cannulation. Their technique involved direct ascending aortic cannulation for initial perfusion, cooling to $24^{\circ} \mathrm{C}$ to $28^{\circ} \mathrm{C}$ (moderate hypothermia), and directly cannulating the innominate artery by inserting a short-tip 9F cardioplegia cannula through a horizontal mattress suture. The left

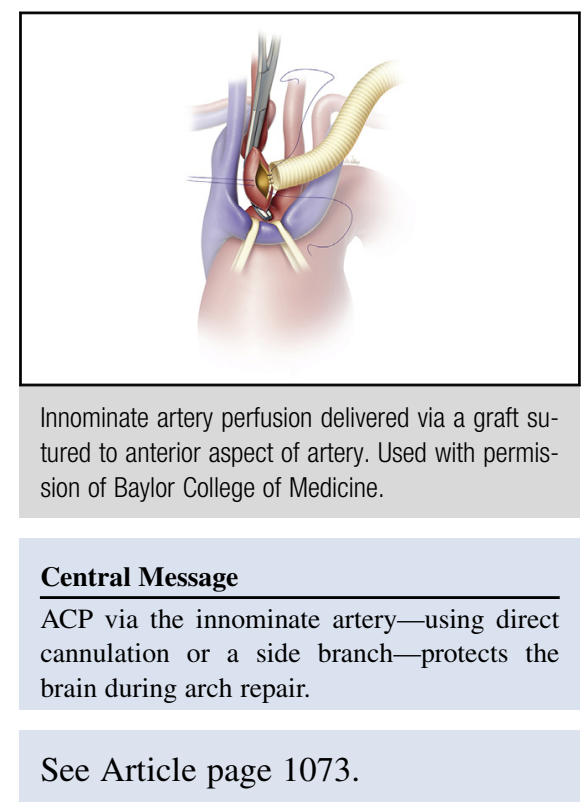

carotid and left subclavian arteries are neither perfused nor occluded, and after the distal anastomosis is completed, cardiopulmonary bypass is reestablished directly through the aortic graft. The results were excellent-only 1 death $(1 \%)$ and 2 postoperative neurologic events $(2 \%)$, neither of which resulted in permanent neurologic deficit. The patients were a select group: All underwent hemiarch replacement of a distal ascending/proximal aortic arch, and it appears that none had aortic dissection or an emergency procedure. In addition, none had anatomic injuries or dissection of the innominate artery. The authors concluded that their technique is safe and yields excellent results.

The case against axillary artery access is that it requires an additional incision and, consequently, extra operative time. Also, although axillary inflow provides excellent initial flow and is clearly a useful adjuvant to ACP, there is risk to the brachial plexus. We have previously described a series ${ }^{7}$ of 68 patients who underwent a wider variety of arch operations, including aortic dissection repair and total aortic arch replacement in which an 8-mm end-to-side graft was anastomosed to the distal innominate artery for both cardiopulmonary bypass inflow and ACP support (Figure 1). Thirty-day mortality was low at $1.5 \%$, and the permanent stroke rate was $2.2 \%$. We then reported using a similar technical approach in a larger series ${ }^{8}$ of 263 patients, with excellent results. Mortality and stroke were $4.9 \%$ and $1.9 \%$, respectively, in a series that included emergency cases, aortic dissection, acute and chronic aortic 


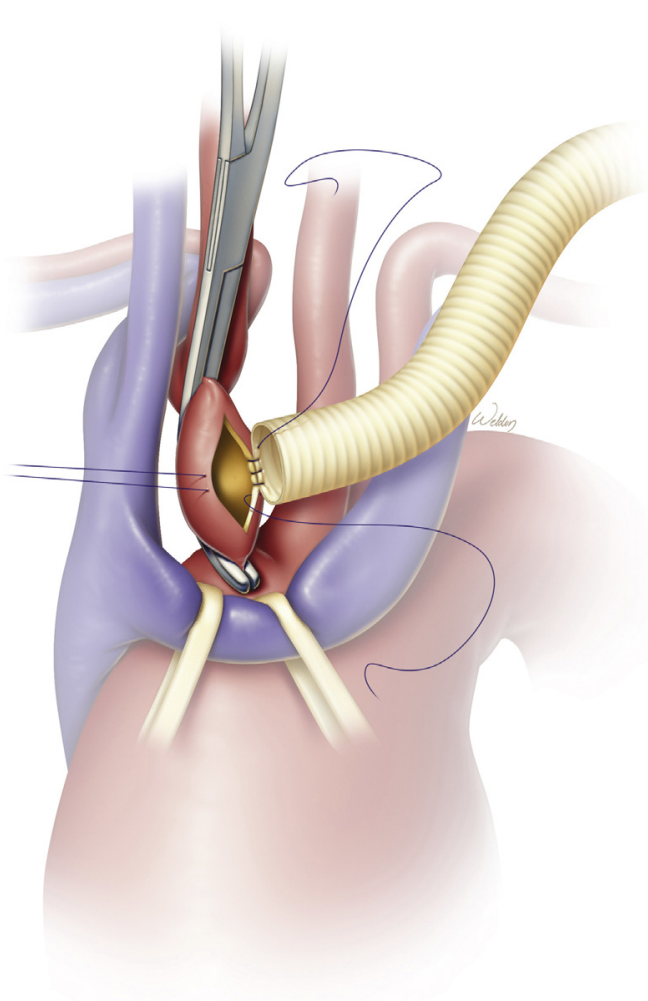

FIGURE 1. Innominate artery cannulation. After $1 \mathrm{mg} / \mathrm{kg}$ of heparin is given, a partial occluding clamp is applied to the distal aspect of the artery, a longitudinal arteriotomy is created, and an $8-\mathrm{mm}$ graft is sewn onto the anterior aspect of the artery in an end-to-side fashion. The graft is carefully flushed and de-aired and is then attached to the inflow line from the cardiopulmonary bypass circuit to provide systemic hypothermic circulatory arrest and antegrade cerebral perfusion. Used with permission of Baylor College of Medicine.

dissection, and total aortic replacement. Our experience with this technique now exceeds 470 cases.
Jassar and colleagues ${ }^{6}$ have provided additional clinical support for the safety and effectiveness of ACP, most notably at moderate temperatures, and for the use of the innominate artery as an alternative access site for ACP in the treatment of patients with selected aortic pathology. Clearly, this adjunct should represent just one weapon in the armamentarium of cardiothoracic surgeons for managing such problems. One would hope that additional clinical evidence is forthcoming to support the use of this valuable tool in more complex aortic arch procedures, including emergency surgery, acute aortic dissection repair, and total arch replacement.

Scott A. Weldon, MA, CMI, created the illustration. Susan Y. Green, MPH, Sally P. Timko, BA, and Stephen N. Palmer, PhD, ELS, contributed to the editing of the manuscript.

\section{References}

1. Griepp RB, Stinson EB, Hollingsworth JF, Buehler D. Prosthetic replacement of the aortic arch. J Thorac Cardiovasc Surg. 1975;70:1051-63.

2. Ueda Y, Miki S, Kusuhara K, Okita Y, Tahata T, Jinno K, et al. [Surgical treatment of the aneurysm or dissection involving the ascending aorta and aortic arch using circulatory arrest and retrograde perfusion]. Nihon Kyobu Geka Gakkai Zasshi. 1988:36:161-6.

3. Ueda Y, Okita Y, Aomi S, Koyanagi H, Takamoto S. Retrograde cerebral perfusion for aortic arch surgery: analysis of risk factors. Ann Thorac Surg. 1999;67: 1879-82; discussion 91-4.

4. De Bakey ME, Crawford ES, Cooley DA, Morris GC Jr. Successful resection of fusiform aneurysm of aortic arch with replacement by homograft. Surg Gynecol Obstet. 1957;105:657-64.

5. Kazui T, Inoue N, Yamada O, Komatsu S. Selective cerebral perfusion during operation for aneurysms of the aortic arch: a reassessment. Ann Thorac Surg. 1992;53:109-14.

6. Jassar AS, Vallabhajosyula P, Bavaria JE, Gutsche J, Desai N, Williams ML, et al. Direct innominate artery cannulation: an alternate technique for antegrade cerebral perfusion during aortic hemiarch reconstruction. J Thorac Cardiovasc Surg. 2016:151:1073-8.

7. Preventza O, Bakaeen FG, Stephens EH, Trocciola SM, de la Cruz KI, Coselli JS. Innominate artery cannulation: an alternative to femoral or axillary cannulation for arterial inflow in proximal aortic surgery. J Thorac Cardiovasc Surg. 2013;145: S191-6.

8. Preventza O, Garcia A, Tuluca A, Henry M, Cooley DA, Simpson K, et al. Innominate artery cannulation for proximal aortic surgery: outcomes and neurological events in 263 patients. Eur J Cardiothorac Surg. 2015;48:937-42. 